UDK 528.14

\title{
KOORDINAČIŲ MATAVIMO TIKSLUMAS, NUSTATANT KADASTRINIŲ SKLYPŲ PLOTUS
}

\author{
Jonas Skeivalas ${ }^{1}$, Edita Alekniené ${ }^{2}$ \\ Geodezijos ir kadastro katedra, Vilniaus Gedimino technikos universitetas, \\ Saulètekio al. 11, LT-10223 Vilnius-40, Lietuva, \\ el.paštas: ${ }^{1}$ Jonas.Skeivalas@ap.vtu.lt, ${ }^{2}$ Edita.Alekniene@ap.vtu.lt
}

Iteikta 200405 10, priimta 20040614

\begin{abstract}
Santrauka. Straipsnyje analizuojamas koordinačių matavimo tikslumas, nustatant reikiamu tikslumu kadastrinių sklypu plotus. Gautos formulès sklypu plotu dispersijai skaičiuoti, ivvertinant tašku koordinačių kovariacijos itaką. Išvestos formulès koordinačių prieaugių ir koordinačių kovariacijų matricoms sudaryti, plotų nustatymo procedūrose taikant poligonometriją. Ivertintas prognozuojamas taškų koordinačių matavimo tikslumas žinant apriorini plotų nustatymo tikslumą.
\end{abstract}

Raktažodžiai: ploto dispersija, koordinačių kovariacija.

\section{Ivadas}

Kartografinių duomenu bazių, kadastro bei įvairiu inžinerinių projektu sudarymo kokybè priklauso nuo geodezinių matavimų rezultatų patikimumo bei tikslumo [1]. Dabar atliekant geodezinius matavimus taikomi poligonometrijos ir GPS (Global Positioning System) metodai [2-4]. Taikant šiuos metodus, taškų koordinatėms bei kitų parametrų reikšmėms nustatyti naudojami elektroniniai tacheometrai ir GPS imtuvai. Straipsnyje analizuojamas kadastrinių sklypų plotu skaičiavimo tikslumas, kai taškų koordinačių tikslumas iš anksto žinomas. Gautos formulès reikiamam tašku koordinačiu tikslumui skaičiuoti pagal nusistatytaji sklypų plotu tikslumą. Nagrinejjama taškų koordinačių kovariacijos itaka nustatant prognozuojamą taškų koordinačių matavimo tikslumą.

\section{Sklypų plotų tikslumo įvertinimo teoriniai principai}

Pagrindiné formulè, taikoma sklypų plotams $Q$ skaičiuoti pagal išmatuotas taškų koordinates, yra Gauso formulè. Yra dvi šios formulès išraiškos:

$$
\begin{aligned}
& Q=\frac{1}{2} \sum_{i=1}^{n} x_{i}\left(y_{i+1}-y_{i-1}\right)=\frac{1}{2} \boldsymbol{X}^{T} \overline{\Delta \boldsymbol{Y}}, \\
& Q=\frac{1}{2} \sum_{i=1}^{n} y_{i}\left(x_{i-1}-x_{i+1}\right)=\frac{1}{2} \boldsymbol{Y}^{T} \overline{\Delta \boldsymbol{X}},
\end{aligned}
$$

čia $x_{i}, y_{i}-$ taškų koordinatès, $\quad \boldsymbol{X}=\left(x_{1}, \ldots, x_{n}\right)^{T}$, $\boldsymbol{Y}=\left(y_{1}, \ldots, y_{n}\right)^{T}, \quad \overline{\Delta \boldsymbol{X}}=\left(\overline{\Delta x}_{1}, \overline{\Delta x}_{2}, \ldots, \overline{\Delta x_{n}}\right)^{T}$, $\overline{\Delta \boldsymbol{Y}}=\left(\overline{\Delta y}_{1},{\overline{\Delta y_{2}}}_{2}, \ldots, \overline{\Delta y_{n}}\right)^{T}$.

Ploto dispersiją galima nustatyti taikant matematinès statistikos dèsnius:

$$
\sigma_{Q}^{2}=\frac{1}{4}\left\{\sum_{i=1}^{n}\left(\frac{\partial Q}{\partial x_{i}}\right)_{0}^{2} \sigma_{x_{i}}^{2}+\sum_{i=1}^{n}\left(\frac{\partial Q}{\partial y_{i}}\right)_{0}^{2} \sigma_{y_{i}}^{2}\right\}
$$

ir toliau -

$$
\sigma_{Q}^{2}=\frac{1}{4}\left\{\sum_{i=1}^{n} \overline{\Delta y}_{i}^{2} \sigma_{x_{i}}^{2}+\sum_{i=1}^{n} \overline{\Delta x}_{i}^{2} \sigma_{y_{i}}^{2}\right\},
$$

čia $\overline{\Delta x}_{i}=x_{i-1}-x_{i+1}, \quad y_{i}=y_{i+1}-y_{i-1} ; \quad \sigma_{x}^{2}, \sigma_{y}^{2}, \sigma_{Q}-$ dispersijų simboliai. Dalinès išvestinès indeksas ()$_{0}$ rodo apskaičiuotą jos reikšmę.

Formulès (3) ir (4) gautos laikant, kad koordinatès yra nekoreliuotos.

Ploto tikslumui ivertinti galima taikyti kovariacija $K_{Q}$, kuri tuo pačiu yra ploto dispersija $\sigma_{Q}^{2}$ ir kurią galima parašyti tokiu pavidalu:

$$
K_{Q}=\sigma_{Q}^{2}=M\left\{(Q-M Q)(Q-M Q)^{T}\right\},
$$

čia $M$ - vidurkio arba matematinès vilties simbolis.

Šiam tikslui atliekame ploto išraiškų (1), (2) linearizavimą:

$$
Q=M Q+\left(\frac{\partial Q}{\partial X}\right)_{0} \boldsymbol{\delta} \boldsymbol{X}+\left(\frac{\partial Q}{\partial Y}\right)_{0} \boldsymbol{\delta} \boldsymbol{Y}
$$

čia $\quad \boldsymbol{\delta} \boldsymbol{X}=\boldsymbol{X}-M \boldsymbol{X}, \quad \boldsymbol{\delta} \boldsymbol{Y}=\boldsymbol{Y}-\boldsymbol{M Y}-\quad$ koordinačių atsitiktinių klaidų vektoriai.

Ploto formulių (1), (2) dalinių išvestinių išraiškas matricu pavidalu gauname taikydami [1]:

$$
\frac{\partial Q}{\partial X}=\frac{1}{2} \overline{\Delta \boldsymbol{Y}}^{T}, \frac{\partial Q}{\partial Y}=\frac{1}{2} \overline{\Delta \boldsymbol{X}}^{T} .
$$


Panaudodami išraišką (6) iš formulès (5) gauname tokị kovariacijos $K_{Q}$ pavidalą:

$$
\begin{aligned}
& K_{Q}=\sigma_{Q}^{2}=\frac{1}{4} M\left\{\left(\overline{\Delta \boldsymbol{Y}}^{T} \boldsymbol{\delta} \boldsymbol{X}+\overline{\Delta \boldsymbol{X}}^{T} \boldsymbol{\delta} \boldsymbol{Y}\right)\left(\overline{\Delta \boldsymbol{Y}}^{T} \boldsymbol{\delta} \boldsymbol{X}+\overline{\Delta \boldsymbol{X}}^{T} \boldsymbol{\delta} \boldsymbol{Y}\right)^{T}\right\}=\frac{1}{4}\left(\overline{\Delta \boldsymbol{Y}}^{T} \boldsymbol{K}_{x} \overline{\Delta \boldsymbol{Y}}+\overline{\Delta \boldsymbol{Y}}^{T} \boldsymbol{K}_{x y} \overline{\Delta \boldsymbol{X}}+\right. \\
& \left.+\overline{\Delta \boldsymbol{X}}^{T} \boldsymbol{K}_{y x} \overline{\Delta \boldsymbol{Y}}+\overline{\Delta \boldsymbol{X}}^{T} \boldsymbol{K}_{y} \overline{\Delta \boldsymbol{X}}\right)=\frac{1}{4}\left(\overline{\Delta \boldsymbol{Y}}^{T} \boldsymbol{K}_{x} \overline{\Delta \boldsymbol{Y}}+2 \overline{\Delta \boldsymbol{Y}}^{T} \boldsymbol{K}_{x y} \overline{\Delta \boldsymbol{X}}+\overline{\Delta \boldsymbol{X}}^{T} \boldsymbol{K}_{y} \overline{\Delta \boldsymbol{X}}\right)
\end{aligned}
$$

čia $\boldsymbol{K}_{X Y}, \boldsymbol{K}_{Y X}-$ koordinačių vektorių $\boldsymbol{X}$ ir $\boldsymbol{Y}$ tarpusavio kovariacijų matricos; $\boldsymbol{K}_{X}, \boldsymbol{K}_{Y}-$ atitinkamų vektorių kovariacijų matricos.

Tašku koordinates, nustatytas GPS imtuvais absoliučiojoje koordinačiu sistemoje, galima laikyti nekoreliuotomis. Tuomet formulè (7) igauna paprastesni pavidalą:

$$
\begin{aligned}
& K_{Q}=\sigma_{Q}^{2}=\frac{1}{4}\left(\overline{\Delta \boldsymbol{Y}}^{T} \boldsymbol{K}_{X, \text { diag. }} \overline{\Delta \boldsymbol{Y}}+\overline{\Delta \boldsymbol{X}}^{T} \boldsymbol{K}_{Y, \text { diag. }} \overline{\Delta \boldsymbol{X}}\right) \\
& \text { čia } \boldsymbol{K}_{X, \text { diag. }}=\left(\sigma_{x_{1}}^{2}, \sigma_{x_{2}}^{2}, \ldots, \sigma_{x_{n}}^{2}\right)_{\text {diag }} \\
& \boldsymbol{K}_{Y, \text { diag. }}=\left(\sigma_{y_{1}}^{2}, \sigma_{y_{2}}^{2}, \ldots, \sigma_{y_{n}}^{2}\right)_{\text {diag }} .
\end{aligned}
$$

Absoliučiojoje koordinačiu sistemoje GPS metodu nustatytų taškų koordinačių tikslumas yra maždaug vienodas. Santykiniu metodu taško padètis nustatoma santykinejje koordinačių sistemoje tų taškų atžvilgiu, kurių koordinatès žinomos ir laikomos tvirtomis. Taikant santykinị metodą, taškų, išdèstytų ne didesniu kaip 10 km atstumu, koordinačiu tikslumas bus maždaug vienodas. Šiais atvejais plotų tikslumo ịvertinimo formulès (4), (8) tampa paprastesnès, nes $\sigma_{x_{1}} \approx \ldots \approx \sigma_{x_{n}}, \quad \sigma_{y_{1}} \approx \ldots \approx \sigma_{y_{n}}$, $\sigma_{x_{i}} \approx \sigma_{n_{i}}$. Taigi visais šiais atvejais galima gauti formules reikiamam tašku koordinačių tikslumui skaičiuoti pagal reikiamą sklypų plotų tikslumą.

Pagal formulę (4) galima parašyti:

$$
\sigma_{x_{i}} \approx \sigma_{y_{i}}=\frac{2 \sigma_{Q}}{\sqrt{\sum_{1}^{n}\left(\overline{\Delta x}_{i}^{2}+\overline{\Delta y}_{i}^{2}\right)}}=\frac{2 \sigma_{Q}}{\sqrt{\sum_{1}^{n} \bar{S}_{i}^{2}}},
$$

čia $\bar{S}_{i}=\sqrt{\overline{\Delta x}_{i}^{2}+\overline{\Delta y}_{i}^{2}}-i$-osios stygos, jungiančios taškus su numeriais $i+1$ ir $i-1$, ilgis.

\section{Sklypų plotų tikslumo ivertinimas taikant poligonometriją}

Kadastrinių sklypu taškų koordinatès, nustatytos poligonometrijos metodu, tampa koreliuotomis. Koreliaciją lemia tai, kad poligonometrijos eigu linijų direkciniai kampai apskaičiuoti pagal išmatuotus poligonometrijos eigu kampus. Poligonometrijos metodu nustatytų taškų koordinačių vektoriai išreiškiami formulemis:

$$
\begin{aligned}
& \boldsymbol{X}=\boldsymbol{X}_{0}+\boldsymbol{A} \cdot \Delta \boldsymbol{X}, \\
& \boldsymbol{Y}=\boldsymbol{Y}_{0}+\boldsymbol{A} \cdot \Delta \boldsymbol{Y},
\end{aligned}
$$

čia $\boldsymbol{X}_{0}, \boldsymbol{Y}_{0}$ - pradinio taško koordinačių vektoriai; $\Delta \boldsymbol{X}, \Delta \boldsymbol{Y}-$ linijų ilgių koordinačių prieaugių vektoriai; $\boldsymbol{A}$ - koeficientų kvadratinè matrica $(n \times n)$. Matrica $\boldsymbol{A}$ sudaroma pagal poligonometrijos tinklo schemą ir atrodo taip [5]:

$$
\boldsymbol{A}=\left(\begin{array}{cccc}
1 & 0 & \ldots & 0 \\
1 & 1 & \ldots & 0 \\
\ldots & \ldots & \ldots & \ldots \\
1 & 1 & \ldots & 1
\end{array}\right) .
$$

Koordinačių vektoriai $\boldsymbol{X}_{0}, \boldsymbol{Y}_{0}$ yra:

$$
\begin{aligned}
& \boldsymbol{X}_{0}=x_{0} \boldsymbol{e}_{n 1}, \\
& \boldsymbol{Y}_{0}=y_{0} \boldsymbol{e}_{n 1},
\end{aligned}
$$

čia $e_{n 1}=\left(\begin{array}{llll}1 & 1 & \ldots & 1\end{array}\right)^{T}$.

Koordinačių prieaugių vektoriai $\Delta \boldsymbol{X}, \Delta \boldsymbol{Y}$ skaičiuojami taip:

$$
\begin{aligned}
& \Delta \boldsymbol{X}^{\boldsymbol{T}}=\boldsymbol{S}^{T} \cos \boldsymbol{\alpha}_{\text {diag }}, \\
& \Delta \boldsymbol{Y}^{\boldsymbol{T}}=\boldsymbol{S}^{T} \sin \boldsymbol{\alpha}_{\text {diag }},
\end{aligned}
$$

čia $S=\left(S_{1}, S_{2}, \ldots, S_{n}\right)^{T}-$ linijų ilgių vektorius, $\boldsymbol{\alpha}=\left(\alpha_{1}, \alpha_{2}, \ldots, \alpha_{n}\right)_{\text {diag }}-$ liniju direkciniu kampu istrižinè matrica.

Nustatysime bendrosios koordinačiu vektoriu struktūros kovariacijų matricą $\boldsymbol{K}\left(\begin{array}{l}\boldsymbol{X} \\ \boldsymbol{Y}\end{array}\right)$ blokiniu pavidalu:

$$
\left(\begin{array}{l}
\boldsymbol{X} \\
\boldsymbol{Y}
\end{array}\right)=\left(\begin{array}{c}
\boldsymbol{X}_{0} \\
\boldsymbol{Y}_{0}
\end{array}\right)+\left(\begin{array}{c}
\boldsymbol{A} \Delta \boldsymbol{X} \\
\boldsymbol{A} \Delta \boldsymbol{Y}
\end{array}\right)
$$


Toliau gauname:

$$
\begin{aligned}
& \boldsymbol{K}\left(\begin{array}{l}
\boldsymbol{X} \\
\boldsymbol{Y}
\end{array}\right)=\left(\begin{array}{cc}
\boldsymbol{K}_{X} & \boldsymbol{K}_{X Y} \\
\boldsymbol{K}_{Y X} & \boldsymbol{K}_{Y}
\end{array}\right)= \\
& =M\left\{\left[\begin{array}{l}
\boldsymbol{A} \boldsymbol{\delta}(\Delta \boldsymbol{X}) \\
\boldsymbol{A} \boldsymbol{\delta}(\Delta \boldsymbol{Y})
\end{array}\right]\left[\begin{array}{c}
\boldsymbol{A} \boldsymbol{\delta}(\Delta \boldsymbol{X}) \\
\boldsymbol{A} \boldsymbol{\delta}(\Delta \boldsymbol{Y})
\end{array}\right]^{T}\right\}= \\
& =\left(\begin{array}{c}
\boldsymbol{A} \boldsymbol{K}_{\Delta X} \boldsymbol{A}^{T} \\
\boldsymbol{A \boldsymbol { K } ( \Delta \boldsymbol { Y } , \Delta \boldsymbol { X } )}
\end{array} \boldsymbol{A}^{T} \mid \frac{\boldsymbol{A} \boldsymbol{K}(\Delta \boldsymbol{X}, \Delta \boldsymbol{Y}) \boldsymbol{A}^{T}}{\boldsymbol{A} \boldsymbol{K}_{\Delta Y} \boldsymbol{A}^{T}}\right),
\end{aligned}
$$

čia $\boldsymbol{\delta}(\Delta \boldsymbol{X}), \boldsymbol{\delta}(\Delta \boldsymbol{Y})$ - koordinačių prieaugių atsitiktinių klaidų vektoriai; $\boldsymbol{K}_{\Delta X}, \boldsymbol{K}_{\Delta Y}, \boldsymbol{K}(\Delta \boldsymbol{X}, \Delta \boldsymbol{Y})$ - koordinačių prieaugiu vektoriu atitinkamos kovariacijų matricos.

Bendroji koordinačių prieaugių vektorių $\Delta \boldsymbol{X}, \Delta \boldsymbol{Y}$ kovariacijų matricos $K\left(\begin{array}{l}\Delta \boldsymbol{X} \\ \Delta \boldsymbol{Y}\end{array}\right)$ struktūra blokiniu pavidalu:

$$
\boldsymbol{K}\left(\begin{array}{c}
\Delta \boldsymbol{X} \\
\Delta \boldsymbol{Y}
\end{array}\right)=\left(\begin{array}{cc}
\boldsymbol{K}_{\Delta X} & \boldsymbol{K}(\Delta \boldsymbol{X}, \Delta \boldsymbol{Y}) \\
\boldsymbol{K}(\Delta \boldsymbol{Y}, \Delta \boldsymbol{X}) & \boldsymbol{K}_{\Delta Y}
\end{array}\right)
$$

čia $\boldsymbol{K}(\Delta \boldsymbol{X}, \Delta \boldsymbol{Y})=\boldsymbol{K}^{T}(\Delta \boldsymbol{Y}, \Delta \boldsymbol{X})$,

$$
\begin{aligned}
& \boldsymbol{K}(\Delta \boldsymbol{X}, \Delta \boldsymbol{Y})= \\
& =\left(\begin{array}{cccc}
K\left(\Delta x_{1}, \Delta y_{1}\right) & K\left(\Delta x_{1}, \Delta y_{2}\right) & \ldots & K\left(\Delta x_{1}, \Delta y_{n}\right) \\
K\left(\Delta x_{2}, \Delta y_{1}\right) & K\left(\Delta x_{2}, \Delta y_{2}\right) & \ldots & K\left(\Delta x_{2}, \Delta y_{n}\right) \\
\ldots & \ldots & \ldots & \ldots \\
K\left(\Delta x_{n}, \Delta y_{1}\right) & K\left(\Delta x_{n}, \Delta y_{2}\right) & \ldots & K\left(\Delta x_{n}, \Delta y_{n}\right)
\end{array}\right) .
\end{aligned}
$$

Pavienių koordinačių prieaugių kovariacijos yra [2]:

$$
\begin{aligned}
& K\left(\Delta x_{i}, \Delta x_{j}\right)=\Delta \tilde{y}_{i}, \Delta \tilde{y}_{j} K\left(\alpha_{i}, \alpha_{j}\right), \\
& K\left(\Delta y_{i}, \Delta y_{j}\right)=\Delta \tilde{x}_{i}, \Delta \tilde{x}_{j} K\left(\alpha_{i}, \alpha_{j}\right), \\
& K\left(\Delta x_{i}, \Delta y_{j}\right)=-\Delta \tilde{y}_{i}, \Delta \tilde{x}_{j} K\left(\alpha_{i}, \alpha_{j}\right), \\
& K\left(\alpha_{i}, \alpha_{j}\right)=i \cdot \sigma_{\beta}^{2}(\text { kai } i<j),
\end{aligned}
$$

$\sigma_{\alpha_{i}}^{2}=i \cdot \sigma_{\beta}^{2}, \Delta \tilde{x}_{i}, \Delta \tilde{y}_{i}-$ koordinačiu prieaugių vidurkiai.

Koordinačių prieaugių dispersijos, kovariaciju matricu $\boldsymbol{K}_{\Delta X}$ ir $\boldsymbol{K}_{\Delta Y}$ istrižiniai nariai skaičiuojami pagal formules:

$$
\begin{aligned}
& \sigma_{\Delta x_{i}}^{2}=\cos ^{2} \tilde{\alpha}_{i} \sigma_{S_{i}}^{2}+\Delta \tilde{y}_{i}^{2} \sigma_{\alpha_{i, r a d}}^{2} \\
& \sigma_{\Delta y_{i}}^{2}=\sin ^{2} \tilde{\alpha}_{i} \sigma_{S_{i}}^{2}+\Delta \tilde{x}_{i}^{2} \sigma_{\alpha_{i, r a d}}^{2}
\end{aligned}
$$

Nepaisydami koordinačių prieaugių kovariacijos, pagal formulę (18) gauname poligonometrijos taškų koordinačių kovariacijų matricu išraiškas:

$$
\begin{aligned}
& \boldsymbol{K}_{X}=\boldsymbol{A} \boldsymbol{K}_{\Delta X} \boldsymbol{A}^{T}= \\
& =\left(\begin{array}{ccccc}
K_{\Delta X_{1}} & K_{\Delta X_{1}} & K_{\Delta X_{1}} & \cdots & K_{\Delta X_{1}} \\
K_{\Delta X_{1}} & \sum_{1}^{2} K_{\Delta X_{i}} & \sum_{1}^{2} K_{\Delta X_{i}} & \cdots & \sum_{1}^{2} K_{\Delta X_{i}} \\
\cdots & \cdots & \sum_{1}^{3} K_{\Delta X_{i}} & \cdots & \sum_{1}^{3} K_{\Delta X_{i}} \\
\cdots & \cdots & \cdots & \cdots & \cdots \\
K_{\Delta X_{1}} & \sum_{1}^{2} K_{\Delta X_{i}} & \sum_{1}^{3} K_{\Delta X_{i}} & \cdots & \sum_{1}^{n} K_{\Delta X_{i}}
\end{array}\right),
\end{aligned}
$$

$$
\begin{aligned}
& \boldsymbol{K}_{Y}=\boldsymbol{A} \boldsymbol{K}_{\Delta Y} \boldsymbol{A}^{T}= \\
& =\left(\begin{array}{ccccc}
K_{\Delta Y_{1}} & K_{\Delta Y_{1}} & K_{\Delta Y_{1}} & \cdots & K_{\Delta Y_{1}} \\
K_{\Delta Y_{1}} & \sum_{1}^{2} K_{\Delta Y_{i}} & \sum_{1}^{2} K_{\Delta Y_{i}} & \cdots & \sum_{1}^{2} K_{\Delta Y_{i}} \\
\cdots & \cdots & \sum_{1}^{3} K_{\Delta Y_{i}} & \cdots & \sum_{1}^{3} K_{\Delta Y_{i}} \\
\cdots & \cdots & \cdots & \cdots & \cdots \\
K_{\Delta Y_{1}} & \sum_{1}^{2} K_{\Delta Y_{i}} & \sum_{1}^{3} K_{\Delta Y_{i}} & \cdots & \sum_{1}^{n} K_{\Delta Y_{i}}
\end{array}\right),
\end{aligned}
$$

čia $K_{\Delta x_{i}}=\sigma_{\Delta x_{i}}^{2}, K_{\Delta y_{i}}=\sigma_{\Delta y_{i}}^{2}$.

Pateiksime pavyzdi, nustatydami kvadrato formos kadastrinio sklypo taškų koordinačių matavimo tikslumą, priklausomai nuo sklypo ploto ir jo numatomo tikslumo. Pagal formulę (9) parašome:

$$
\sigma_{x} \approx \sigma_{y}=\frac{2 \sigma_{Q}}{\sqrt{\sum_{1}^{4} \bar{S}_{i}^{2}}}=\frac{\sigma_{Q}}{Q} \frac{a}{\sqrt{2}}
$$

čia $a$ - kvadrato kraštinès ilgis, $\bar{S}_{i}^{2}=2 a^{2}$.

Skaičiavimu rezultatai pagal sklypo plotą ir jo reikiamą tikslumą parodyti lentelëje.

\begin{tabular}{|l|l|l|}
\hline $\begin{array}{l}\text { Sklypo } \\
\text { plotas, } \\
\text { ha }\end{array}$ & $\begin{array}{l}\text { Koordinačiu standartiniai nuokrypiai } \\
\sigma_{x} \approx \sigma_{y}, \mathrm{~m}\end{array}$ \\
\cline { 2 - 3 } & kai $\sigma_{Q} / Q=1 \%$ & kai $\sigma_{Q} / Q=3 \%$ \\
\hline 1,0 & 0,7 & 2,1 \\
\hline 10 & 2,2 & 6,6 \\
\hline 100 & 7,0 & 21 \\
\hline
\end{tabular}

Šios reikšmès yra apriorinès. Didelio ploto kadastriniuose sklypuose taškų, ribojančių sklypą, esti ne daugiau kaip 4. Todèl šiais atvejais sklypo tašku koordinates taip pat būtina nustatyti tiksliau remiantis formule (9).

Parodysime tuo pačiu paprastu pavyzdžiu, kaip neteisingai ivertinamas sklypo ploto tikslumas, kai skaičiavimams panaudojamos ne visų taškų koordinatès. Kvadratinio sklypo plotą galima užrašyti

$$
Q=a^{2}=\Delta x^{2}+\Delta y^{2}
$$


ir

$$
\sigma_{Q}^{2}=(2 \Delta x)^{2} \sigma_{\Delta x}^{2}+(2 \Delta y)^{2} \sigma_{\Delta y}^{2}=4 a^{2} \sigma_{\Delta x}^{2}=8 a^{2} \sigma_{x}^{2},
$$

čia $\sigma_{\Delta x}=\sqrt{2} \sigma_{x}, \sigma_{\Delta y}=\sqrt{2} \sigma_{y}, \sigma_{x} \approx \sigma_{y}$.

Taigi turime

$$
\sigma_{x} \approx \sigma_{y}=\frac{\sigma_{Q}}{Q} \frac{a}{2 \sqrt{2}} .
$$

Pagal šią formulę reikiamas matavimų tikslumas neatitinka būtinojo sklypo ploto tikslumo pagal pasirinktaji sklypo ploto tikslumą. Šiuo atveju gautume perpus mažesnes koordinačių matavimo standartinių nuokrypių reikšmes, palyginti su jų realiomis reikšmėmis. Taip atsitiko todèl, kad sklypo plotui ir jo tikslumui nustatyti buvo panaudotos tik vienos kraštinès dvieju taškų koordinatės. Kitų dviejų taškų koordinatès nebuvo panaudotos, taigi nepaisyta ir šių koordinačių klaidų. Taip pat neatsižvelgta i funkcinę koordinačių kovariaciją. Todèl procedūros rezultatas - klaidingas ploto tikslumo ivertis.

\section{Išvados}

1. Rekomenduojama formule (7) ploto tikslumui nustatyti, įvertinant taškų koordinačių kovariacijos įtaką.

2. Pasiūlytos formules (18-25) koordinačiu prieaugių ir koordinačių kovariacijų matricoms nustatyti, plotų nustatymo procedūrose taikant poligonometriją.

3. Parodyta, kad sudarant plotų tikslumo įvertinimo formules turi būti atsižvelgta i visų taškų koordinačių klaidas. Priešingu atveju - gaunamas klaidingas plotu tikslumo rodiklis.

\section{Literatūra}

1. Koch, K. R. Parameterschätzung und Hypothesentests. Dümmlers Verlag, Bonn, 1997. 366 p.

2. Skeivalas, J.; Aleknienè, E.; Anikènienè, A. The parameters of the accuracy of geodetic networks in the economical development projects. Geodesy and Cartography (Geodezija ir kartografija), Vol XXIX, No 4 , Vilnius: Technika, 2003, p 128-130 (in Lithuanian).

3. Petroškevičius, P. Gravitation field effect on geodetic observations (Gravitacijos lauko poveikis geodeziniams matavimams). Vilnius: Technika, 2004. 292 p (in Lithuanian).

4. Balandynowicz, J.; Dabrowski, W.; Gasowska, B. Restorable networks strengthened by GPS vectors. Geodesy and Cartography (Geodezija ir kartografija), Vol XXVI, No 3. Vilnius: Technika, 2000, p 116-122.

5. Skeivalas, J. Treatment of correlated geodetic measurements. (Koreliuotu geodeziniu matavimu rezultatu matematinis apdorojimas). Vilnius: Technika, 1995. $272 \mathrm{p}$ (in Lithuanian). 